\title{
Vallejo, Vargas Vila. Oposición, redundancia
}

Vallejo, Vargas Vila: opposition and redundancy

Vallejo, Vargas Vila. Oposição, redundância

\section{Juan Carlos González Espitia}

UNIVERSITY OF NORTH CAROLINA AT CHAPEL HILL, ESTADOS UNIDOS

Profesor del Departamento de Literaturas y Lenguajes Romances en

University of North Carolina at Chapel Hill, Estados Unidos.

$\mathrm{PhD}$, Cornell University, Estados Unidos. Autor de On the Dark

Side of the Archive: Nation and Literature in Spanish America at

the Turn of the Century (Bucknell University Press, 2010), y con

William J. Acree Jr., coeditor de Building Nineteenth-Century Latin

America: Re-Rooted Cultures, Identities, and Nations (Vanderbilt

University Press, 2009). Correo electrónico: jcge@unc.edu

Artículo de reflexión

Documento accesible en línea desde la siguiente dirección: http://revistas.javeriana.edu.co

doi:10.11144/Javeriana.CL19-37.vavi 


\section{Resumen}

En este artículo Juan Carlos González Espitia interroga el papel de Vallejo como intelectual. Mediante un análisis de las filiaciones del discurso de Vallejo con Vargas Vila, el artículo evalúa lo que la tensa división de opiniones en el ámbito público con respecto a estos dos autores separados por un siglo puede aportar en la definición de qué es el intelectual en América Latina. Su análisis explora las formas en que tanto Vargas Vila como Vallejo ejercen su papel de polémicos y heterodoxos productores de opinión. Al enfocarse principalmente en la repetición que satura la obra y la opinión de Vallejo como una forma de oposición a la redundancia totalizante del discurso hegemónico, González Espitia hace un importante aporte a la comprensión de la compleja dimensión política del discurso de Vallejo.

Palabras clave: Fernando Vallejo; intelectual history; hegemony José María Vargas Vila; historia intelectual; hegemonía

\section{Abstract}

In this article, Juan Carlos

González Espitia questions

Vallejo's role as an intellectual.

Through an analysis of the affiliation of Vallejo's discourse with Vargas Vila, the article evaluates the ways in which the tense division of opinions in the public sphere, with respect to these two authors separated by a century, may contribute to the definition of what being an intellectual is in Latin America. His analysis explores how both Vargas Vila and Vallejo exercise their roles as controversial and unorthodox opinion producers. By focusing mainly on the repetition that saturates Vallejo's work and opinion, as a type of opposition vis-à-vis the allencompassing redundancy of the hegemonic discourse, González Espitia makes an important contribution to the political dimension of Vallejo's discourse. Key words: Fernando Vallejo; José María Vargas Vila;

\section{Resumo}

Neste artigo, Juan Carlos González Espítia interroga sobre o papel de Vallejo como intelectual. Através de uma análise das filiações do discurso de Vallejo com Vargas Vila, o texto avalia o que a tensa divisão de opiniões no âmbito público com respeito a estes dois autores separados por um século pode aportar na definição do que é o intelectual na América Latina. Suas análises exploram as formas com que tanto Vargas Vila como Vallejo exercem seu papel de polêmicos e heterodoxos produtores de opinião. Ao se focar principalmente na repetição que satura a obra e os juízos de Vallejo como uma forma de oposição à redundância totalizante do discurso hegemónico, González Espítia oferece um importante subsídio à compreensão da complexa dimensão política do discurso de Vallejo.

Palavras-chave: Fernando Vallejo; José María Vargas Vila; história intelectual; hegemonia 
BASTARDO, inCRÉDUlO, ANTIPATRIÓtico, apátrida, vulgar, ignorante, contradictorio, blasfemo, mentiroso, extravagante, traidor. Visionario, brillante, rico, hosco, conmovedor, maestro, valiente, atrevido, magistral. Estos son algunos de los adjetivos que he encontrado para calificar la obra de Fernando Vallejo; pero es claro que han sido escritos más específicamente para calificarlo a él y a su personaje público. Fue fácil encontrar estas referencias en comentarios cibernéticos de los últimos ocho o diez años, y todo lo que necesité fue escribir unas pocas palabras clave en el teclado de mi computador.

Bastardo, degenerado, disociador, malhablado y despreciable, impío, desnaturalizado, mentiroso, satánico, enemigo de la paz, el orden y la autoridad. Decadente, pernicioso, blasfemo, expatriado, antipatriótico, degenerado. Maestro, valiente, directo, guerrero, defensor de la democracia, liberal, conmovedor, divino. Un poco más difícil fue encontrar este nuevo conjunto de adjetivos, pues no aparece tanto en los blogs, los clips de YouTube, o los artículos de prensa actuales. Estas palabras se utilizaron por los últimos cien años para describir la obra de José María Vargas Vila (1860-1933); pero, como en el caso de Vallejo, se trata más bien de descriptores de él y de su imagen pública.

Los paralelismos evidentes entre estos autores colombianos van más allá de la alabanza y la condena que comparten con respecto a sus buenos o malos lectores. Aunque la mayoría de comentarios sobre sus similitudes tienden a aparecer en notas salpicadas en sitios de discusión electrónica u otras máquinas de opinión pública a las que ya nos hemos acostumbrado, contamos con algunos estudios serios sobre sus afinidades electivas. Mi intención aquí no es revisitar esas sincronías, sino, más bien, usándolos a ellos dos como ejemplos paradigmáticos, explorar brevemente la relación entre la figura del intelectual hispanoamericano y la percepción ambivalente de la figura pública del escritor o del artista. Esta tensa división se ve claramente en el tipo de adjetivos polarizados que se han usado para describir a estos escritores y que acabo de mencionar. ¿Qué es lo que representan estos dos actores culturales que hace que a un mismo tiempo unos los caractericen como "maestros"; mientras que otros los señalan como "bastardos"? Mi propuesta es que la evaluación de la tensa división de opiniones en el ámbito público con respecto a Vargas Vila y Vallejo puede ser una herramienta constructiva y útil en nuestra búsqueda de definición de lo que es el intelectual para esta región.

Me limito aquí a marcar algunos hitos de la noción del intelectual, discutir ese concepto aplicado a Vallejo y Vargas Vila, y señalar cómo los engloba a 
pesar del largo paréntesis de tiempo que hay entre los dos. ${ }^{1}$ En la segunda parte desarrollo una discusión sobre la idea de redundancia como una característica estratégica de estos dos autores que los diferencia claramente de otros emisores de opinión en su función como intelectuales. La tarea es más compleja de lo que parece, pues exige una revisión focalizada de lo que es el intelectual latinoamericano, un meollo que otros han abordado con mucha más perspicacia de la que yo podría tener. Este es un concepto de múltiples capas con lecturas divergentes, y, en consecuencia, tenemos mucho y muy poco con qué trabajar. En ese sentido, yo reconozco que mi aporte aquí es provisional, limitado, parcial y, en algunos lugares, contradictorio.

Una buena parte de los problemas para poder precisar el concepto del intelectual en Hispanoamérica se deriva de la fuerte influencia de académicos importantes cuyo trabajo, como suele ser el caso, nos ayuda a enmarcar ideas generales útiles, pero cuya aproximación encumbrada al mismo tiempo calcifica o fosiliza la interpretación. Un ejemplo arquetípico de este efecto abarcador pero inflexible es el de José Ortega y Gasset (1883-1955). Para este último el papel del intelectual está restringido a una acción común y diaria, pero eminentemente aislada. En su "Prólogo para franceses", de La rebelión de las masas (1937), indica sobre sí mismo como intelectual que:

[...] mi trabajo es oscura labor subterránea de minero. La misión del llamado 'intelectual' es, en cierto modo, opuesta a la del político. La obra intelectual aspira, con frecuencia en vano, a aclarar un poco las cosas, mientras que la del político suele, por el contrario, consistir en confundirlas más de lo que estaban. Ser de la izquierda es, como ser de la derecha, una de las infinitas maneras que el hombre puede elegir para ser un imbécil: ambas, en efecto, son formas de la hemiplejía moral. (53)

Para él, el intelectual es intrínsecamente diferente del artista, y aún más radicalmente afirma que no hay manera de conjugar el arte y la vida cotidiana. La consecuencia de esta caracterización, que posiblemente no era la que Ortega buscaba, es que se considere que el artista no tiene nada que hacer en la vida pública, de la polis, que su obra se ha de limitar exclusivamente a la esfera de lo estético, y en ese mismo sentido que es opuesta a lo político. En cuanto al intelectual, Ortega

1 En el ensayo "Vargas Vila, intelectual", próximo a aparecer en Revista Iberoamericana, he desarrollado una discusión más detallada sobre Vargas Vila en este rol público. Tomo de allí algunas ideas con el objetivo de hacer el seguimiento hasta la instancia de Vallejo y como una manera de establecer una línea sobre la idea del intelectual entre el fin de siglo XIX y el fin del siglo XX. 
afirma con razón que su trabajo es arrojar luz sobre las preguntas de "el hombre y la naturaleza y la historia, qué es la sociedad y el individuo, la colectividad, el Estado, el uso, el derecho"; mientras que el trabajo de los políticos y la política es apresurarse "a apagar las luces para que todos estos gatos resulten pardos" (54). Incluso si él tiene razón en esta evaluación, el resultado es parcializante, porque entonces el intelectual no debería tener injerencia en la producción de cambios directos, más humildes y menos metafísicos, en el ámbito público. En el mismo sentido, un artista, un escritor, por ejemplo, que se entromete en la vida pública tendría que entenderse como alguien que traiciona su misión estética. En otras palabras, el efecto de esta perspectiva de Ortega es que se entiende que el artista o el intelectual no debe ensuciarse las manos con las preguntas menos luminosas que atañen el aquí y el ahora. La situación parece complicarse, aún más, si se sigue la línea de Ortega de que el artista no debe inmiscuirse en el terreno de indagación del intelectual, y si lo hace estaría rayando en abominación. Así, el artista no es lo mismo, o no debe ser lo mismo, que el intelectual. Así, ni el artista ni el intelectual, que se supone tampoco ha de ser un artista, estarían llamados a intervenir en la política pública.

La otra vía arquetípica que facilita pero que al mismo tiempo limita la comprensión del papel del intelectual en América Latina es la poderosa aproximación desarrollada por el influyente académico uruguayo Ángel Rama (1926-1983), en su obra La ciudad letrada. Según Rama, en el proceso de afianzamiento del poder de la metrópoli española en las colonias:

[...] para llevar adelante el sistema ordenado de la monarquía absoluta, para facilitar la jerarquización y concentración del poder, para cumplir su función civilizadora, resultó indispensable que las ciudades, que eran el asiento de la delegación de los poderes, dispusieran de un grupo social especializado, al cual encomendar esos cometidos. Fue también indispensable que ese grupo estuviera imbuido de la conciencia de ejercer un alto ministerio que lo equiparaba a una clase sacerdotal. (31)

El problema con la interpretación de Rama no es lo que él dice, sino nuestra recepción reduccionista o de oídas de su trabajo que ha terminado por hacernos pensar que él estaba haciendo una comparación tautológica entre "letrado" e "intelectual". En realidad lo que está indicando Rama es que el "letrado" -o mejor, los letrados artificiales, que es el término que Rama toma prestado de José Martí(61) - usa su capacidad de producción textual para mantener la prevalencia del statu quo y, en consecuencia, para mantener su propia situación de privilegio, esto es, aquella "poderosa articulación letrada que rodea al poder, manejando los 
lenguajes simbólicos en directa subordinación de las metrópolis [...] el anillo protector del poder y el ejecutor de sus órdenes" (32). En ese sentido, aunque la inconsistencia en el uso de los términos por parte de Rama a veces produzca confusión, el "letrado" no es el mismo que el "intelectual" hispanoamericano, porque este intelectual está relativamente escindido de los beneficios que otorga el sistema hegemónico. En oposición a la caracterización del letrado, surge la imagen y trabajo de productores de textualidades en el largo siglo XIX en Latinoamérica que podríamos señalar en una lista que incluiría a personajes como Juan Montalvo (1832-1889), José Martí (1853-1895), Rubén Darío (1867-1916) o Alfonso Reyes (1889-1959). Lo que llama la atención es que este tipo de agentes condensan un compromiso político que no necesariamente está a favor del statu quo - de este modo contradiciendo la perspectiva de Ortega y reformulando la Rama-y una exploración estética radical - de nuevo impugnando la propuesta del madrileño cuando indicaba que el artista no tiene que ver con el intelectual.

Estudiosos como Mabel Moraña, Julio Ramos y Carlos Alonso nos han proporcionado importantes revisiones a la perspectiva de Rama, indicándonos que es necesario reinterpretar su trabajo mediante una exploración heterodoxa. Yo pienso que lo mismo debe hacerse con respecto a la propuesta de Ortega y Gasset, añadiendo a lo anterior la necesidad de una metodología sencilla que nos haga ver que cada producción artística está inmersa en su tiempo y en su lugar. Para proporcionar nueva flexibilidad a las teorizaciones de críticos como Rama u Ortega se precisa revisar de dónde viene el concepto del intelectual en el siglo XIX. El 13 de enero de 1898, Émile Zola (1840-1902) publicó en el periódico L'Aurore su famosa carta abierta titulada "J'Accuse", en que denunciaba al gobierno de Félix Faure (1841-1899) por el injusto encarcelamiento del capitán de origen judío Alfred Dreyfus (1859-1935) bajo el cargo de vender secretos militares a los alemanes. Uno de las principales acusaciones de Zola contra el gobierno de Faure era la de antisemitismo. Un día después de la aparición de la carta, el director del periódico, Georges Clemenceau, publicó el "Manifeste des Intellectuels" [Manifiesto de los intelectuales], firmado por un numeroso grupo de escritores y artistas que apoyaban la acusación de Zola contra el gobierno y los altos militares (Johnston 43). Hasta ese momento la palabra intelectual se había utilizado muy raramente $y$, por lo general, para señalar a alguien como diletante y persona pretenciosa, pero a partir de ese momento se convirtió en sinónimo de los productores públicos de opinión, esto es, las personas que expresan un juicio sobre lo que está bien o mal (Szacki 231).

Así, la creación del concepto de intelectual está directamente conectada con la creación de directrices sobre los asuntos públicos de todos los días. En 
ese sentido, el concepto del intelectual heredaba las ideas propias de la Revolución Francesa - entre otras el derecho a la diferencia, la noción de igualdad o la confianza en el conocimiento como fuente de libertad-, y ya desde entonces se oponía a una interpretación ligera de Ortega y Gasset en el sentido de que el papel del intelectual está directamente relacionado con la producción artística. A lo anterior se suma que Zola y muchos de los firmantes del manifiesto eran figuras artísticas que ahora se proyectaban más allá del marco de su trabajo estético personal. Este momento de incepción del concepto también rebate nuestra lectura parcial de la propuesta de Rama, porque claramente aquí el intelectual, aunque inevitablemente sea parte del universo del ajetreo político, no es un defensor del statu quo o de las personas en el poder.

Zola y Hugo, grandes ejemplos europeos de la conjunción de esfuerzo literario y compromiso político, sirvieron como modelos destacados para la joven generación de escritores a la que Vargas Vila pertenecía. Esta conjunción es de vital importancia en la definición del intelectual del siglo XIX y el de la actualidad en la América hispanohablante, pues contra lo que nos ha enseñado o sugerido la crítica tradicional - en parte sustentada por una lectura parcial de autores como Rama-, el intelectual no es necesariamente el mismo que el erudito o el "letrado". Del mismo modo, el estudio del momento de incepción del concepto del intelectual en el siglo XIX nos permite desmitificar la otra idea manida entre nosotros los críticos - y que no se deriva de la obra de Rama, debo aclarar - de poner en la misma caja erudición y literatura. El resultado de este ofuscamiento es que hemos terminado por convencernos erradamente de que la intelectualidad es lo mismo que "buena" o "alta" literatura, o que todos los intelectuales son grandes escritores, o que un escritor que no es muy bueno no puede ser un intelectual o, peor aún, que para ser intelectual se debe ser escritor.

Hechas las aclaraciones anteriores, ahora se puede tratar de ver el concepto del intelectual hispanoamericano de otro modo, especialmente teniendo en cuenta que su característica más clara es su voluntad de intervenir en los asuntos públicos de su tiempo y lugar. En otras palabras, el intelectual es uno interesado en el ejercicio público de la política, entendiendo política en su sentido lato de actividad que busca influir en las acciones o decisiones de un gobierno o de una sociedad. Si hemos de tener en cuenta las características que he descrito sobre la creación del concepto y el papel del intelectual, en nuestros días esta tarea parece haberse desplazado hacia las personas involucradas en el activismo social; mientras que, en general, el interés del autor literario parece haber virado más hacia premios literarios insulares o peninsulares o hacia los movimientos del mercado literario. Por supuesto, esta tendencia señalada tiene muchas excepciones y confirmaciones. 
Como se puede ver, estoy apuntando hacia la caracterización de Vargas Vila y Vallejo como ejemplos relevantes del intelectual latinoamericano. A pesar de que los dos están ubicados dentro de sus circunstancias históricas como incisivos e influyentes productores de juicios, también los dos se ubican por fuera de la norma establecida y producen un juego dinámico entre la ortodoxia y la heterodoxia. Las afinidades electivas entre estos dos autores apoyan la idea de que su producción escritural funciona casi como un sistema de vasos comunicantes que conecta dos siglos. En su calidad literaria, la producción de Vallejo y Vargas Vila no es diferente al común denominador de otros pensadores hispanoamericanos y cada uno en su tiempo ha articulado la realidad y la identidad en términos estéticos. Aun en los muchos momentos en los que estos autores describen su entorno con detalles repulsivos o toscos, sus descripciones se mantienen dentro de los límites de una normatividad estéticamente mediada, es decir, informada por la idea de lo bello, aunque sea oponiéndose a ello. Sus descripciones perturbadoras son, en verdad, la manifestación del deseo de mostrar una puerta de escape para los muchos proyectos fallidos en la región ya desde el siglo XVIII. En este sentido, Vargas Vila y Vallejo deben entenderse como intelectuales, cuya función es incomodar tanto a su público ideal (desde el exilio) como a la comunidad en que residen (como exiliados). Su papel tiende a ser localizado, y en ese sentido obedece a necesidades temporales, ataca y al mismo tiempo adopta las idiosincrasias locales, y su lenguaje es capaz de registrar y adoptar los cambios resultantes de la discusión con una solo propósito fijo: la oposición.

Por supuesto, tal espíritu de antagonismo solo es posible cuando el antagonista puede ejercer su antagonismo desde un punto de vista antagónico. Este no es solo un juego de palabras, porque quiero insistir en que la oposición de Vallejo y Vargas Vila únicamente es eficaz cuando sus argumentos como intelectuales pueden ser tan ampliamente escuchados como los del statu quo: el poder de influencia del intelectual, su capacidad para ser escuchado atentamente, está directamente relacionado con su nivel de prestigio. Aquí surge otro componente importante que nos lleva a definir con mayor precisión quién es y qué función cumple el intelectual hispanoamericano que encarnan los dos, pues este prestigio tiene que ver con la manera en que el intelectual se mantiene vigente en el ojo del público. Una de las fuentes etimológicas de la palabra prestigio - del latín praestigia, que es también el verdadero origen de la palabra prestidigitador - tiene que ver con la idea de ilusión, de la fuerte impresión que se puede ejercer sobre un público, de la creación de fascinación. Si bien el statu quo tiene a su servicio canales de todo tipo que le permiten reproducir su discurso, el intelectual también usa su capacidad de producir impresión o crear fascinación para mantener 
la atención del público. Contraria a la idea que tenemos del intelectual como aquel personaje que se reserva para iluminarnos con sus grandes verdades, à la Ortega y Gassett, este intelectual hispanoamericano tiene una relación mucho más ligera, espontánea, excéntrica y, sobre todo, inmediata con su público y con su momento. Este prestigio, alejado de la idea de sobriedad, mesura y reflexión metafísica, se traduce paradójicamente en respetabilidad para dar relevancia a sus enjuiciamientos, pero no necesariamente respetabilidad en el sentido tradicional de dignidad, sino más bien - la etimología es útil de nuevo - en el sentido de que ser respetado es ser visto o considerado en dos ocasiones, ser tenido en cuenta más allá de la primera impresión. Esta cualidad del intelectual se evidencia claramente en Vargas Vila y Vallejo, quienes desarrollan poderosas estrategias de autorrepresentación, autopromoción y autoentronización. Algunos pueden llamar a esto megalomanía, y puede que tengan razón - los que estamos en el mundo académico podemos dar fe de que esta es una característica muy propia de aquellos que emitimos opiniones-, pero es claro que esta proyección forzada del discurso propio es posiblemente una de las únicas opciones disponibles en el ámbito latinoamericano para que estos productores de opinión mantengan influencia y vehículos para canalizar sus juicios.

Estas estrategias de búsqueda y cultivo de audiencias son las que con mayor frecuencia se ven en el continente y que, en general, han marcado la presencia continuada de Vargas Vila y Vallejo. Algunos ejemplos que demuestran esta característica arquetípica son la ya mítica imagen de Vargas Vila negándose a arrodillarse delante del papa León XIII, o Vallejo renegando de su nacionalidad colombiana, Vargas Vila llamando al escritor argentino Leopoldo Lugones (1874-1938) un "Payaso cascabelero de La Nación, de Buenos Aires, ese Esclavo Nubio, ebrio del Orín de las caballerizas de la Prensa, Filibustero de la Reacción, a sueldo de todos los despotismos, vendutero de sus Pasiones, ya que no tiene Ideas con las cuales comerciar" (Odisea 107), o Vallejo, con un estilo injurioso que emparienta claramente con el que acabo de citar de Vargas Vila cuando criticó en una conferencia pública al entonces presidente de Colombia Álvaro Uribe Vélez: "- ${ }_{\mathrm{C}}$ Este hombrecito? Este culibajito no puede ni con su alma. Es más alto de estatura física, que de la moral, y de la intelectual ni se diga" ("Explosiva conferencia").

Respetabilidad y prestigio son interdependientes con la visibilidad, la perspectiva y, muy especialmente, la capacidad para incomodar al statu quo. Como se ve, estas características son muy diferentes a las esbozadas por nuestra lectura tradicional de críticos como Ortega y Gasset o Rama - y más afines a la creación del término intelectual de $1898-$ y nos permiten identificar la particularidad del 
intelectual hispanoamericano de no estar necesariamente ligado a una agenda inmutable, ni compelido a seguir una lógica política. El cambio, la revisión, la incoherencia y la imprevisibilidad son características intrínsecas que Vallejo o Vargas Vila usan como intelectuales para proyectar su voz y su subjetividad. Cuando hablo de subjetividad, me refiero a que la participación de este tipo de intelectuales es localizada y política - es decir, ligada pero no en connivencia con la autoridad y el poder-y, en ese sentido, no reclama necesariamente para sí la categoría de verdad. En lugar de "la Verdad", lo que buscan estos intelectuales es una validez que busca marcar la invalidez de la posición del statu quo. Esta dinámica convierte al intelectual en un entrometido, en una piedra en el zapato, un impertinente, una molestia dañina o, en palabras de Jean-Paul Sartre, "es un hecho que un intelectual es alguien que no evita meterse en lo que no le importa" (12). Es esta cualidad proteica lo que produce la reacción ambigua o ambivalente de los calificativos hechos por amigos y enemigos de estos dos autores que consigné al principio de este ensayo, y que muestran todos los pelambres del espectro, desde aquellos que los nombran como bastardos, pasando por los que los llaman valientes, hasta aquellos que los vitorean como maestros. A pesar de la gran variedad de oprobios y alabanzas lo que queda claro es que ambos autores como intelectuales han logrado su objetivo de no ser considerados irrelevantes.

Otra forma de manifestación proteica e intersticial que influye en el rol de Vargas Vila y Vallejo como intelectuales es la expatriación. El haberse ido de su país de origen les ha permitido establecer una triangulación de su experiencia y de su voz que los hace presentes y ausentes a la vez. La ambivalencia entre pertenencia y expulsión, o entre pertenencia y diferencia, galvanizan su juicio y les sirve como plataforma desde la que se hacen oír y desde la que se hacen rechazar. La residencia en esta fisura indeterminada los ubica en una posición muy estratégica de expresión tanto en su entorno (en el que son extranjeros) como en los lugares de los que han sido proscritos. El malestar vacilante e imperfecto retratado en la obra de estos dos autores, un malestar que fluctúa entre la glorificación y el insulto, nos ofrece en este esfuerzo por marcar hitos una característica más del intelectual latinoamericano: él o ella es un individuo cuyo centro vital es el ejercicio constante de la disidencia como forastero.

El intelectual es voluble y por eso algunos lo llaman traidor, pero desde la perspectiva amplia que he tratado de describir aquí observamos que esa cualidad mudable es coherente con su objetivo de mantener la triangulación estratégica entre la adhesión y el rechazo. El efecto de este tipo de triangulaciones es que debilita la capacidad del statu quo para imposibilitar la eficacia de las pretensiones de los intelectuales. Por ejemplo, aun cuando haya un coro de blogueros que 
acusa a Vallejo de no vivir en la realidad colombiana, de no entender esa realidad por no vivir en ella y de expresar opiniones que no son válidas por no estar conectado físicamente con el país, eso no quiere decir que la opinión de Vallejo no se escuche o que sus juicios e invectivas no produzcan un efecto en aquellos o aquello que buscaba atacar. En realidad lo que sucede es todo lo contrario, su posición como un automarginado, como autoexiliado hace que sus constantes declaraciones sean más eficaces. Es en el intersticio entre la aceptación y la expulsión, expresada repetidamente y públicamente a favor y públicamente en contra de la sociedad - es decir, intelectualmente- donde el poder de estos dos escritores mantiene su prevalencia.

Dentro de esta dinámica oposicional se ha acusado a Vargas Vila y Vallejo, hasta cierto punto con razón, de ser repetitivos e insistentes en su producción literaria y en su criticismo. Creo que el mejor término para nombrar el efecto que ellos producen es el de redundancia: estos dos intelectuales colombianos son redundantes. El término es útil, porque tiene su origen en una palabra latina ( $r e$ dundantia, y sé que debo presentar mis excusas por esta mi manía etimológica), que se relaciona con la idea de desbordamiento, y en ese sentido abarca tanto la repetición como el exceso con que se ha caracterizado su obra. Dentro de un discurso más reciente relacionado con la lingüística, la computación y las matemáticas, pero que mutatis mutandis me sirve aquí en mi evaluación de la idea del intelectual hispanoamericano, la caracterización de redundancia es igualmente útil, porque apunta hacia la reiteración de una idea más allá de lo que normalmente se considera necesario, pero que permite que el mensaje no se pierda, aun cuando partes de ese mensaje se pierdan, se malinterpreten o se distorsionen. $^{2}$

En un nivel muy básico y cotidiano, la repetición es lo que sucede cuando aquel que quiere ser escuchado no es atendido o cuando el interlocutor con quien se quiere establecer la comunicación no entiende lo que se le dice. Yo creo que esta interpretación primaria explica mucho del papel de Vallejo y Vargas Vila como intelectuales, porque sus insistencias obedecen al deseo de ir más allá de la formulación de una crítica. La defensa de posiciones críticas frente a la sociedad

2 La tercera acepción del término en el Diccionario de la lengua española, de la Real Academia Española, se refiere a este camino de interpretación: "Cierta repetición de la información contenida en un mensaje, que permite, a pesar de la pérdida de una parte de este, reconstruir su contenido". Esta aproximación, que por lo general se refiere a elementos de una máquina o a constituyentes de un sistema de información digital, permite ver la redundancia como la repetición de funciones que no permite que toda la máquina o todo el sistema fallen si una de esas partes que redundan llegase a fallar. 
es una constante de larga tradición. Por ejemplo, desde siempre se ha criticado a los tiranos y a los que abusan de su poder, pero eso no significa que la mera formulación de esa crítica haya logrado acabar con un tirano en particular. Es la repetición y la reformulación constante del disenso en un contexto determinado la que produce el cambio en un caso particular y en una sociedad definida. Fue la insistencia repetida, la redundancia de muchas personas públicas en Francia que con su firma respaldaron a Zola la que produjo un resultado más justo frente a la situación de Dreyfus en 1898 de la que hablé al inicio de este ensayo, y fue la insistencia monotemática sobre los derechos civiles llevada a cabo por Martin Luther King Jr. y sus seguidores la que logró cambios tangibles para la minoría afroamericana en los Estados Unidos. Es esta misma insistencia excesiva la que satura la obra y opinión de los dos colombianos que atañen aquí, con la característica importante de que para ellos está revestida de un cariz eminentemente artístico, es decir, impregnado por el estilo y la cualidad poética.

No se trata aquí entonces de un oficio en que se emiten constante y periódicamente opiniones, como sería el caso de una columna editorial, o el de los opinadores de profesión en programas noticiosos, o los anfitriones de programas de opinión. Si bien el columnista expresa su visión de disenso, la regularidad obligada de sus opiniones, lo mismo que la amplitud de temas contingentes - $y$, a decir verdad, vacuos las más de las veces - que tiene que tratar periódicamente, hace que pierda mucho de la concentración en el ataque que tiene un autor que imbrica la producción artística con la de su opinión. La potencia del efecto reiterativo de intelectuales como Vargas Vila y Vallejo radica en que sus afirmaciones están movidas por su pasión. Con esto no quiero decir que un columnista no pueda tener la función de un intelectual, solo que las columnas de opinión no tienen por lo general el componente literario o el referente literario que estos dos autores en particular pueden usar estratégicamente para su beneficio.

La redundancia como exceso es la otra faceta importante de estos dos autores como intelectuales y tiene relación directa con otras características con las que se les reconoce, como el insulto y la disputa acerva contra todo lo que se yergue como tradicional y establecido. Este tipo de redundancia también revela que Vallejo y Vargas Vila insisten sobre los mismos temas, los mismos argumentos y las mismas imágenes, porque consideran que no han sido escuchados o que si han sido escuchados no han sido entendidos o, aún más radicalmente, que aún no se han entendido a sí mismos. Una muestra de esa desazón se hace evidente en un pasaje de Vargas Vila en que, a pesar de la comprobada popularidad de sus obras, teme no haber logrado ser interpretado de manera adecuada: "No ser leído, debe ser muy triste; pero no ser comprendido por aquellos que nos leen 
es la más grande de todas las tristezas" (Saudades tácitas 203). La otra muestra es la respuesta de Vallejo a una pregunta, también repetitiva, de la entrevistadora María Paulina Ortiz sobre si el autor va a escribir más novelas: “ ¿Es decir que en El don de la vida no está todo lo que quiso decirle a la muerte?", pregunta Ortiz. A lo que Vallejo responde, "No, todavía no acabo, me da para varios libros más, empecinados, repetitivos, rabiosos" ("La muerte con Fernando Vallejo"). En una entrevista con Ricardo Castro, publicada en revista Arcadia, en febrero de 2013, Vallejo reflexiona con mayor profundidad sobre la manera en que su repetición temática sobre la muerte no es otra cosa que una reflexión sobre la repetición en la vida de todas las personas en la sociedad contemporánea:

Ricardo Castro: Después de Entre fantasmas, La Rambla paralela y El don de la vida, serán cuatro novelas sobre el tema de su muerte ${ }_{\mathrm{C}}$ siente que se le escapa lo que quiere contar sobre el tema?

Fernando Vallejo: Lo que tengo claro es que no puedo escribir sino sobre eso porque ya me voy a morir. Lo he tratado antes y cada día soy más consciente de cómo me repito y de cómo me estoy repitiendo. Pero ¿quién no se está repitiendo toda la vida? Nos repetimos todos los días. Cambiamos un poquitito de lunes a viernes, pero en todos los instantes nos estamos repitiendo adentro. ("Tengo que demoler la sociedad")

Por otro lado, la insistencia de Vallejo por la defensa de los animales sabemos que ha donado el dinero de sus premios a instituciones humanitarias, que ha aparecido en escenarios acompañado por perros abandonados, que ha comentado sobre su amor a sus mascotas vivas y muertas - tiene que ver con su deseo de mantenerse dentro de la discusión que de otro modo quedaría relegada simplemente como otro más de los lugares comunes de la agenda liberal y políticamente correcta como la preservación del medio ambiente, la igualdad salarial para hombres y mujeres, la negociación justa entre pequeños productores agrícolas y las grandes multinacionales o el consumo de productos orgánicos. Frente al constante, pero en últimas ineficaz, bombardeo de estos lugares comunes, la voz de Vallejo, mediada por su éxito literario y su heterodoxia estratégica, se constituye en una fuente de insistencia o redundancia que mantiene, así sea de manera ríspida, la atención sobre algo que él considera no ha sido escuchado o comprendido. Pero este exceso reiterativo es también la reacción necesaria frente a las circunstancias de tiempo y lugar que estos dos autores han tenido que confrontar, pues la redundancia de su voz crítica se opone a la redundancia totalizante del discurso hegemónico. Esto es, además de fijar una posición personal, la redundancia discursiva de un autor como Vallejo o Vargas Vila sirve para 
contrarrestar un discurso hegemónico igualmente redundante que se mantiene en pie mediante el ataque sin cuartel contra la diferencia bajo la excusa de la concordia, la unidad o la tradición.

Sea cual fuere el camino de interpretación, la efectividad de la redundancia estratégica de Vallejo se manifiesta en los constantes ataques que recibe - solo hay que recordar aquellos con que inicié este ensayo-, y que han alcanzado incluso el nivel de lo legal, por su crítica reiterada al dogma católico, la iglesia y el papa. ${ }^{3}$ Esta redundancia de parte y parte produce el efecto de vínculo indisoluble entre el intelectual y una causa definida, que en el caso de Vallejo se observa, por ejemplo, con la defensa de los animales y, en el caso de Vargas Vila, en su anticlericalismo radical.

Como ya he comentado en In the Dark Side of the Archive, yo creo que esta posición acerva de Vargas Vila y Vallejo se debe a una falta de centro causada por su situación de ambigüedad y ansiedad, esto es, por su deseo fundamental y fallido de lograr la normalidad perdida - aun si esta normalidad es solo una imaginación-que únicamente puede conjugarse en tiempo pasado. Estos dos autores en el exilio presentan una insistente evocación de la infancia y la juventud que, como toda memoria, no parece ser real sino construida artificialmente por la reiteración y fraguada narrativamente. Cuando Vallejo rememora de una manera y otra la finca Santa Anita de la que era dueña su abuela Raquel Pizano, logra poner ese pasado como marca idealizada que aunque no es veraz, sí es cierta y segura. Del mismo modo, Vargas Vila insiste recurrentemente en la memoria del país como causa perdida, simplemente porque la elevación de la derrota ideológica se constituye en punto de apoyo seguro. Esta narrativización redundante, que funciona como prótesis del lugar perdido pero seguro, les sirve a estos autores como intelectuales para atacar rudamente lo que ven como fallido en el presente. Al lugar arcádico de Santa Anita se contrapone para Vallejo la actual corrupción en Colombia o la ineficacia de sus políticos. A los logros sociales alcanzados por las políticas liberales de fin de siglo XIX en su país, Vargas Vila contrapone lo que

3 En 2006, el entonces consejero de Estado, hoy procurador general de la nación de Colombia, Alejandro Ordóñez Maldonado, lideró una demanda contra la revista SoHo y contra Vallejo por la publicación de un artículo en que el autor atacaba el dogma católico. El texto de Vallejo venía acompañado por unas fotos en que una modelo desnuda aparecía personificando a Jesús en una imagen de la última cena: "Los demandantes argumentan, apelando al artículo 203 del Código Penal, que las fotos en cuestión, y el artículo de Fernando Vallejo que las acompañaba, constituían en un agravio al culto, y que eso era penalizado por la ley con una multa. Además, señalaban que en el caso del director de la revista y del autor del artículo, también se podía tipificar el delito de injuria y calumnia, que contempla una pena de uno a tres años de prisión" ("La hora de la verdad"). El caso precluyó agosto del mismo año. 
él ve como retroceso producido por la injerencia de la Iglesia católica en asuntos del Estado que trajeron Rafael Núñez (1825-1894) y la Regeneración en Colombia.

Pero esta redundancia en el contraste entre pasado y presente no es únicamente el resultado de una estrategia para lograr un objetivo de cambio. La insistencia en la narración de los mismos nodos de significado también tiene que ver con que para estos autores la pérdida del pasado idealizado ha producido un golpe tan contundente en sus personas que pareciera que no han podido rebasarlo, que se han quedado atascados a tal punto en ese dolor que han terminado por convertirlo en el motor que genera buena parte de su producción literaria, caracterizada casi siempre como una literatura de oposición o de visión pesimista de la realidad. Un buen ejemplo del cruce de redundancia, memoria y dolor que contrasta presente y pasado en Vallejo es la descripción de cadáveres decapitados que flotan en el río Cauca como resultado de la violencia partidista de la década de los cuarenta y de los cincuenta en Colombia, y que el observara con sus propios ojos durante su infancia. Vallejo anuncia esta imagen bajo la rúbrica de la violencia repetida pero no resuelta en su discurso "El monstro bicéfalo", que pronuncia en septiembre de 1998 ante el Primer Congreso de Escritores Colombianos:

[...] les voy a recordar unos nombres: El Dovio, Fresno, Irra, Salento, Armero, La Línea, Letras, Icononzo, Supía, Anserma, Cajamarca, El Águila, Falan. El genocidio de El Dovio, el genocidio de Fresno, el genocidio de Irra, el genocidio de Salento, el genocidio de Armero, el genocidio de La Línea, el genocidio de Letras, el genocidio de Icononzo, el genocidio de Supía, el genocidio de Anserma, el genocidio de Cajamarca, el genocidio de El Águila, el genocidio de Falan, ¿̇qué? ¿'Nunca ocurrieron? Centenares de campesinos decapitados, extendidos en fila por el suelo con las cabezas asignadas por manos caritativas a los cuerpos a la buena de Dios. ¡Qué! ¿Colombia ya los olvidó? ¿Es que con tanto muerto le entró el mal de la desmemoria y se le borró la historia? A mí no. Pues esos genocidios se cometieron en nombre de los principios irrenunciables del gran partido conservador o de los principios irrenunciables del gran partido liberal, según fuera la filiación de los asesinos y del pueblo de los muertos. ("El monstruo")

Pero esta imagen ya había aparecido mucho antes. Vallejo había utilizado el lenguaje fílmico En la tormenta (1980), rodada en México a causa de los obstáculos que tuvo para producirla en Colombia, para dar forma a la idea de que la violencia partidista solo terminaba en cuerpos inertes a la deriva, flotando sobre el río que todo lo recoge, y casi capitaneados por gallinazos negros, sin color 
de partido, como representación del primado de la muerte sobre las ideologías. Ya desde el diálogo inicial entre niños en la película — no se debe olvidar que el recuerdo de la infancia es central en toda la obra del colombiano- se nota que la imagen tiene un profundo significado en la visión que tiene Vallejo de su historia propia y de la de su país:

_ No, el río Verde.

Por ahí fue que bajaron los hombres sin cabeza, yo los vi.

_ Mentiroso, Furi era el que los vio. Sí los vi, sí los vi.

__ Si sigue diciendo mentiras se lo va a llevar el diablo, Satanás que tiene cola. Como los liberales, diablos con cola. (En la tormenta)

La escena de un cuerpo que flota lentamente por el río con un gallinazo encima se repite como imagen cinematográfica en varias ocasiones en la película, y ello apuntala la idea de que los campesinos y los niños son testigos pasivos, e infortunadamente cómplices, de la violencia en el país. Esta fuerte imagen fue presentada de forma narrativa por primera vez por Vallejo en su novela Los días azules, publicada inicialmente en 1985 y reeditada junto con otras de sus novelas heterodoxamente autobiográficas como parte del extenso volumen $E l$ río del tiempo (1999). Aunque allí estos sucesos están todavía adscritos a una reformulación de la historia convencional de la violencia colombiana, sin una fuerte presencia de la subjetividad de su propia memoria, Vallejo sí ha acuñado ya una marca estética y política - característica de su intelectualidad-mediante la descripción de las aves de carroña sobre los cuerpos hinchados y sin cabeza, esto es, sin identidad política o, mejor dicho, como unidos bajo la concordia todopoderosa de la muerte:

[...] la muerte de Gaitán partió la historia de Colombia en dos, con un tajo de machete. Después el machete siguió cortando cabezas. Y los ríos se fueron llenando de decapitados: por un cadáver de conservador que bajaba sin cabeza, bajaba un liberal descabezado. Los gallinazos, apolíticos, gozaban el banquete de la neutralidad instalados sobre unos y otros. (72-73).

Como parte de las motivaciones que he descrito dentro de la conexión entre redundancia e intelectualidad en Vallejo y Vargas Vila, el escritor de Medellín vuelve a visitar la imagen de los decapitados en El desbarrancadero (2001), pero esta vez es más clara la búsqueda de refinamiento literario, aunque este refinamiento sea el de la concentración en la brutalidad de la violencia que el autor siente como estigma no resuelto de la sociedad colombiana: 
Cadáveres decapitados de conservadores y liberales bajaban por los ríos de la patria tripulados por gallinazos que en su viaje de bajada a los infiernos, de ociosos, por el tiempo a falta de alguien más, sin distingos doctrinarios, de partido, les iban sacando a azules y a rojos a picotazos las tripas. (23)

La insistencia -o "perorata" para usar el título de uno de sus libros más recientes - en esta imagen se hace más literaria, más radical y más redundante en La Rambla paralela (2002), uno de los libros más complejos y atípicos dentro de su obra: "sobre los decapitados del río despanzurrándolos: sacándoles, como un niño travieso la cuerda a un reloj, de la panza las tripas". (18)

Con este seguimiento de la genealogía, repetición, origen y variación de una imagen usada por Vallejo, he demostrado que su redundancia tiene relación directa con su objetivo claro de marcar su presencia en el debate sobre la situación política de Colombia no como político ni como politólogo, ni como sociólogo, sino como personaje público y como fuente de una voz fuerte que señala las problemáticas que para otros no son ya más que materia de texto de historia. Pero también he demostrado que esta necesidad de insistir, de abundar o redundar sobre temas específicos es una manifestación de la necesidad de repetir a través del lenguaje lo que se teme pueda repetirse en la realidad. En este sentido, la redundancia es una herramienta muy poderosa para que el intelectual ataque el silencio, que es el paso anterior al olvido. Esta redundancia y repetición también le es importante al intelectual del tipo de Vallejo y Vargas Vila para contrarrestar la conformidad o normalización de la manera en que las cosas de la vida pública son y para señalar a aquellos que están de acuerdo o en desacuerdo con él que "acostumbrarse" no es una alternativa para la sociedad del presente. Es posible que, en este sentido, la condición de exiliado del intelectual sea también una manera de preservar un locus desde el que se pueden formular con claridad, como exceso y como diferencia, las cualidades negativas que los que están dentro del día a día de ese conflicto no pueden ver, y en ese sentido la redundancia es fundamental, porque al tener un efecto acumulativo obliga insidiosamente a que la sociedad a la que está dirigida no ponga su mirada en otra dirección.

Aquí debo detenerme para evitar ser redundante. Pero antes de cerrar esta discusión es necesario comentar sobre dos aspectos relacionados con la idea provisional del intelectual que he estado revisando. Por un lado, debo referirme a la crítica generalizada de que los productores de opinión del tipo de Vallejo y Vargas Vila se dedican a criticar la situación del momento, pero que prácticamente nunca ofrecen soluciones. Esta caracterización puede ser cierta, es posible que no ofrezcan soluciones, pero lo que no es acertado es poner en manos del 
intelectual ofrecer caminos de salida u ofrecer parámetros cercanos a la panacea. En el sentido de la incepción del término intelectual con que inicié este ensayo, lo que hace intelectual a alguien como Zola, o Vargas Vila o Vallejo, es el verbo acusar (yo acuso,j'accuse), revelar, señalar o apuntar, y no el de solucionar, arreglar o aliviar. El otro aspecto que quiero destacar aquí, y que se refiere nuevamente a las causas de la redundancia, es que las manifestaciones de estos intelectuales tienen un alto componente de compromiso personal - lo que antes llamé pasión-que hace que sus posicionamientos estén directamente relacionados con lo que ellos sienten de manera visceral. De ahí también que sus críticas no obedezcan muchas veces a una lógica determinada o a un discurso ideológico preconcebido. Al contrario, de lo que se trata es de una ambigüedad, flexibilidad y falta de centro que es lo que hace su discurso tan potente y eficaz.

Aunque debo aceptar que veo con ojos positivos a este tipo de intelectuales que deciden ponerse en el ojo del huracán para beneficiarse ellos mismos, pero al mismo tiempo para tratar de ejercer un efecto de cambios sobre lo que casi no cambia, no me ha interesado necesariamente hacer aquí hacer una defensa a ultranza de Vallejo o Vargas Vila como héroes. Lo que me ha interesado, eso sí, es tratar de explorar cómo su función pública, que hace que sean calificados en polos completamente opuestos como bastardos o como visionarios, ha hecho mucho bien en promover la discusión. Hasta donde entiendo, la diferencia y la discusión son las verdaderas bases de una democracia.

\section{Obras citadas}

Johnston, William M. "The Origin of the Term 'Intellectuals' in French Novels and Essays of the 189os". Fournal of European Studies 4.1-13 (1974): 43-56.

"La hora de la verdad". SoHo, 13 de julio de 2006: n. pág. Web. 7 de jul. de 2014.

Ortega y Gasset, José. La rebelión de las masas: con un prólogo para franceses, un epílogo para ingleses y un apéndice. Dinámica del tiempo. Madrid: Espasa-Calpe, 1980.

Rama, Ángel. La ciudad letrada. Montevideo: Arca, 1998.

"Redundancia". Diccionario de la lengua española. Madrid: Espasa Calpe, 2001.

Sartre, Jean-Paul. Plaidoyer pour les intellectuels. Paris: Gallimard, 1972.

Szacki,Jerzy. "Intellectuals between Politics and Culture". The Political

Responsibility of Intellectuals. Ed. Ian Maclean, Alan Montefiore y

Peter Winch. Cambridge: Cambridge University Press, 1990.

Vallejo, Fernando. El desbarrancadero. Bogotá: Alfaguara, 2008.

—. "El monstruo bicéfalo". Arquitrave. n. pág. Web. 7 de jul. de 2014.

-. Dir. En la tormenta. Bogotá: Unicornio Films, 2010. Película. 
-. "Explosiva conferencia de Fernando Vallejo en los 10 años de la revista 'El Malpensante"". El Tiempo, 29 de oct. de 2006. n. pág. Web. 7 de jul. de 2014.

-. "La muerte con Fernando Vallejo". El Tiempo, 6 de marzo de 2010. n. pág. Web. 7 de jul. de 2014.

-. Peroratas. Madrid: Alfaguara, 2013.

-. La Rambla paralela. Bogotá: Alfaguara, 2002.

-. El río del tiempo. Bogotá: Alfaguara, 1999.

- . "Tengo que demoler la sociedad, tengo que demoler a Colombia". Arcadia, 19 de feb. de 2013, n. pág. Web. 7 de jul. de 2014.

Vargas Vila,José María. Odisea romántica: diario de viaje a la República argentina. Madrid: Biblioteca nueva, 1927.

-. Saudades tácitas: obra inédita. Barcelona: R. Sopena, 1922. 